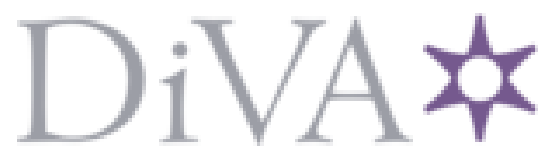

http://www.diva-portal.org

\title{
Postprint
}

This is the accepted version of a paper published in Philosophy. This paper has been peer-reviewed but does not include the final publisher proof-corrections or journal pagination.

Citation for the original published paper (version of record):

Bohlin, H. (2013)

Universal moral standards without an Archimedean point: Hume's refutation of relativism in "A

Dialogue".

Philosophy, 88(4): 593-606

http://dx.doi.org/10.1017/S0031819113000557

Access to the published version may require subscription.

N.B. When citing this work, cite the original published paper.

Permanent link to this version:

http://urn.kb.se/resolve?urn=urn:nbn:se:sh:diva-19981 
Universal Moral Standards and the Problem of Cultural Relativism in Hume's 'A Dialogue'

Henrik Bohlin

Published in Philosophy vol, 88, nr 4, s 593 - 606, http://journals.cambridge.org/repo_A90iwJ4j

Abstract

An interpretation and evaluation is offered of Hume's argument on cultural relativism in the essay 'A Dialogue'. It is argued that Hume sets forth a typology of moral disagreement and for each type disputes the relativist conclusion that right and wrong varies between nations or historical epochs. When there are conflicting views on a moral matter, then either one side can be shown right and the other wrong, by arguments from principles which both sides accept, or more than one reasonable view can exist on the matter, according to the standards of both sides, or the disagreement concerns a morally indifferent matter, or the moral sentiments of at least one disputant are distorted (perverted, 'artificial'). It is concluded that Hume commits himself to a particular form of meta-ethical relativism but not to normative relativism, the idea that what is wrong in one culture can be right in another. When 'artificial' moral sentiments are involved, one cannot resolve disagreement by arguments that are valid for everyone, or even for every ideally rational thinker. Nevertheless, there are universal standards for right and wrong, valid independently of any particular culture or tradition. 


\section{Universal Moral Standards and the Problem of Cultural Relativism in HuMe's ‘A Dialogue’}

Hume's essay 'A Dialogue' was published in 1751 together with the Enquiry Concerning the Principles of Morals. ${ }^{1}$ It addresses the problem of cultural relativism. Are there universal, culturally independent moral standards, or must we conclude from the great variations in moral outlook between cultures and epochs that there exist no universal moral standards, but only a plurality of parochial standards, none of which is preferable over others on universally valid grounds? Hume lets the narrator of his essay argue that there exist universal standards of moral blame and censure, despite the obvious disagreements on derivative issues (Dial. 26; SBN 333). ${ }^{2}$

The argument has been dismissed as depending on the simplistic assumption that cultures differ only in applying shared general principles to diverse circumstances. ${ }^{3}$ As I interpret him, however, Hume puts forward a much more complex and plausible argument, hinging on a typology of disagreement over matters of value and the idea that relativism is the wrong stance on each of these types. Disagreement over matters of value can be what I will call rationally

\footnotetext{
${ }^{1}$ Tom Beauchamp, 'Introduction. A History of the Enquiry on Morals', in David Hume, An Enquiry Concerning the Principles of Morals, ed. Tom Beauchamp (Oxford: Oxford University Press, 1998), xvii, xliii.

${ }^{2}$ David Hume, 'A Dialogue', in Hume, An Enquiry Concerning the Principles of Morals (Oxford: Oxford University Press, 1998), 110-23, abbreviated 'Dial' in the text and cited by paragraph, followed by 'SBN' and the page number in Hume, Enquiries Concerning the Principles of Human Understanding and Concerning the Principles of Morals, ed. L. A. Selby-Bigge, rev. P. H. Nidditch (Oxford: Clarendon Press 1975).

${ }^{3}$ Simon Blackburn, Ruling Passions: A Theory of Practical Reasoning (Oxford: Oxford University Press 1998), 301.
} 
decidable, which means that careful argumentation can in principle either show one side to be right and the other to be wrong, or show right and wrong to depend on circumstances.

Disagreement can also be what I will call rationally compromisable, either because it concerns morally indifferent aesthetic matters, or because moral principles shared by both parties are too imprecise to give unequivocal verdicts on particular matters. Finally, moral disagreement can be rationally uncompromisable if the moral sentiments of one disputant have been distorted by superstition or philosophical enthusiasm.

Without explicitly saying so, Hume implies that this typology is exhaustive and that relativity of the kind insisted upon by philosophical relativists is consequently not a real possibility. In what follows, I will take a closer look at Hume's discussion of each disagreement type and then try to assess the strength of the argument as a whole.

To my knowledge, only two earlier commentators have dealt exclusively with the 'Dialogue'. Kate Abramson places the essay in the context of Hume's moral philosophy in general, and Emilio Mazza examines its historical context and reviews the previous comments on the 'Dialogue' scattered throughout the Hume literature. ${ }^{4}$ By contrast, my purpose is not primarily to place the essay in the context of Hume's thought or in a wider historical context, but to identify the core argument against relativism and appraise its strengths and weaknesses.

\footnotetext{
${ }^{4}$ Kate Abramson, 'Hume on Cultural Conflicts of Values', Philosophical Studies 94, No. 1-2 (1999), 173-187; Emilio Mazza, 'Cannibals in “A Dialogue” (In Search of a Standard for Morals)', in Instruction and Amusement: Le ragioni dell'illuminismo britannicco, eds. Emilio Mazza and Emanuele Ronchetti (Padova: Il Poligrafo, 2005), 4566.
} 


\section{Rationally decidable disagreement}

'A Dialogue' begins with a story reminiscent of Swift's Gulliver's Travels (one of Hume's sources of inspiration). ${ }^{5}$ The narrator's friend Palamedes describes a journey to the strange country of Fourli, where people are highly civilized and intelligent, but where siblings are allowed to marry, murder and suicide are accepted and sometimes even strongly admired, and it is customary for older married men to have open homosexual relations with younger lovers. The narrator, appalled by the account, questions its veracity and argues that such 'barbarous and savage' customs go against human nature (Dial. 12; SBN 328). Palamedes replies that he has all along been talking of the much admired ancient Greeks and Romans, only using exotic names to disguise well-known historical figures. The suicide of the Fourlian Alcheic is a parallel to that of Socrates, the murder of Usbek to that of Caesar, and so on. The real point, he explains, was to demonstrate the cultural relativity of morals.

I only meant to represent the uncertainty of all these judgments concerning characters; and to convince you, that fashion, vogue, custom, and law, were the chief foundation of all moral determinations. The Athenians surely, were a civilized, intelligent people, if ever there were one; and yet their man of merit might, in this age, be held in horror and execration. The French are also, without doubt, a very civilized, intelligent people; and yet their man of merit might, with the Athenians, be an object of the highest contempt and ridicule, and even hatred... How shall we pretend to fix a standard for judgments of this nature (Dial. 25; SBN 333)?

The narrator replies that there is in fact a way to establish such a standard, namely, to identify

\footnotetext{
${ }^{5}$ Mazza, 'Cannibals in "A Dialogue", 55.
} 
the more general and fundamental principles underlying the manifold of moral notions among men. In support of this universalist (anti-relativist) claim, he draws attention to the fact that we are sometimes capable of reaching agreement with others by looking more closely at their conditions of life, or by scrutinizing the arguments for their views and our own carefully enough to identify hidden errors and correct them. This is the first type of moral disagreement, which most obviously bears out the narrator's anti-relativism, and which I call disagreement over rationally decidable issues (the terminology is my own). Such disagreement can arise either because the issue is context dependent, in the sense that right and wrong of the matter is relative to external circumstances, or because it is due to faulty reasoning, so that one party to the conflict (or possibly both) has drawn conclusions that do not follow from shared general principles and the facts or evidence of the particular matter. In both cases, the disputants agree on the relevant general moral principles and disagree only on derivate matters.

Hume argues, for instance, that the general virtue of law obedience may imply rigorous loyalty to the ruler in the absence of a legal system, because public justice then depends entirely on the sovereign, but that the same principle has different implications when applied to countries and historical epochs with well-developed laws and law enforcement (Dial. 33; SBN 335). What distinguishes this contextualist position from relativism? By relativism, I here mean the view that not only what people think is right or wrong but that what is right and wrong, good and bad, virtuous and vicious, vary between cultures, traditions, historical epochs, etc. - in Hume's terms, that there exist no universal standards of rightness and wrongness, or of vice and virtue ('normative relativism', as I call it below). This means that is possible for two disputants to have mutually incompatible views on, say, whether implicit obedience to the ruler was right in the late Roman empire, so that each side provides an unequivocal answer to the question which genuinely 
contradicts that of the other, while each is nevertheless right relative to his own moral perspective. Hume denies this and argues that once the question has been specified to a particular context, it has a universally valid answer.

By contrast, disagreement due to faulty reasoning can in principle if not always in practice be resolved by rational argumentation once the errors are pointed out. ${ }^{6}$ Hume seems to place the murder of Caesar in this category, arguing that it was intended to defend political liberty against the crimes of usurpery and tyranny, and so clearly had something to speak for it, but that the benefits were unambiguously outweighed by the detriments, 'which could any one have proved clearly to the ancients, had he reformed their sentiments in this particular' (Dial. 31; SBN 335).

\section{Rationally compromisable disagreement}

Not all moral matters are rationally decidable. Disagreement can be rationally compromisable (but rationally non-decidable), by which I mean that, reasoning from a common ground of assumptions, each party can recognize the other's view as rationally and morally allowable without for that matter sharing it - one might say that they agree to disagree. This is a compromise in the sense of a limited concession to the other, from one side or both. Such disagreement may be due to imprecision in principles, or it may concern morally indifferent aesthetic matters. (The words 'compromisable' and 'uncompromisable' do not appear in the Oxford English Dictionary, but the verb 'compromise' is listed, one of its meaning being 'come to an agreement by the partial surrender of position or principles'.)

In disagreement due to imprecision, the underlying general moral principles are not in dispute,

\footnotetext{
${ }^{6}$ See Abramson, 'Hume on Cultural Conflicts', 174-175.
} 
but provide equally strong reasons for each of two or more conflicting applications to a particular case. For instance, although sexual relations between close relatives are generally considered to be wrong, this principle does not specify the precise allowable degree of proximity in family relations, and therefore does not answer the question whether it is morally wrong to marry one's half-sibling. The Athenians may have gone too far in one direction by allowing such marriages, or we in the other by banning them (Dial. 29; SBN 334).

Hume's narrator seems to hold a similar view on suicide (Dial. 35; SBN 335), and on the supposed French tolerance for extramarital love relations (sexual 'gallantry'), which he explains by saying that the French

have resolved to sacrifice some of the domestic to the sociable pleasures; and to prefer ease, freedom, and an open commerce, to a strict fidelity and constancy. These ends are both good, and are somewhat difficult to reconcile; nor need we be surprised, if the customs of nations incline too much, sometimes to the one side, sometimes to the other (Dial. 32; SBN 335).

Note that if an issue is morally uncertain or indeterminate in the way Hume describes, then it is so within the systems of moral beliefs of both parties to the disagreement. Debating with the other, each recognizes, or has reason to do so, that the matter was not as straightforward as he first thought and that his own moral standards leave room for more than one view (although despite this he may retain preferences different from the other's).

There is another way in which disagreement over matters of value can be rationally compromisable although impossible to decide one way or the other by argument. Despite the general constancy of moral sentiments, Hume says, there exist 'some minute differences'. For example, while few eighteenth century Britons would find a low forehead and joined eye-brows attractive, the former was considered a mark of beauty by Horace and the latter by the Greek poet 
Anacreon (Dial. 36; SBN 336). These are matters of aesthetic taste, and the principle de gustibus non est disputandum applies to them. That is of course not to say that all questions of taste lack objective answers. On the contrary, when Hume specifically discusses aesthetic judgment in 'Of the Standard of Taste', the main tendency is the same as in 'A Dialogue': to search for general principles or rules 'by which the various sentiments of men may be reconciled; at least, a decision, afforded, confirming one sentiment, and condemning another' ('Of the Standard of Taste', EMPL 229). ${ }^{7}$

\section{Rationally uncompromisable disagreement}

Can there be cases of disagreement such that the disputants can neither resolve them by argument nor rationally agree to disagree about them? Palamedes introduces this possibility by drawing attention to what he calls the 'artificial lives' of the philosophers Diogenes, who 'indulged himself in the most beastly pleasures, even in public', and Pascal, who 'made constant profession of humility and abasement, of the contempt and hatred of himself; and endeavored to attain these supposed virtues, as far as they are attainable'. Again, the narrator is challenged to come up with a universal standard of morals for judging such extraordinary views (Dial. 55-56; SBN 342-343).

In his surprisingly short reply, the narrator concedes that there can in fact be no such standard.

When men depart from the maxims of common reason, and affect these artificial lives, as you call them, no one can answer for what will please or displease them. They are in a different element from the rest of mankind; and the natural principles of their mind play not with the same regularity,

\footnotetext{
${ }^{7}$ David Hume, Essays, Moral, Political, Literary, ed. Eugene F. Miller (Indianapolis: Liberty Fund, 1987),
} abbreviated 'EPML' in the text and cited by page number. 
as if left to themselves, free from the illusions of religious superstition or philosophical enthusiasm (Dial. 57; SBN 343).

This implies the possibility of a third type of disagreement, which I call rationally uncompromisable, and which, according to Hume, involves distorted ('corrupt', 'perverted') moral sentiments on one side or both. In the 'Dialogue', religious superstition and philosophical enthusiasm are mentioned as sources of such sentiments and views (Dial. 57; SBN 343), although the examples are both in the latter category. In other works, particularly The Natural History of Religion, Hume seems to consider religion the main source of perverted reasoning and distorted moral judgment. ${ }^{8}$ Whatever the cause, the effect is that disagreement cannot be resolved by argument. To someone whose moral sentiments are undistorted, the 'artificial' views of someone whose natural moral feelings have been perverted will sometimes be too reprehensible for him to simply accept them as different but equally justified or at least tolerable moral views, and there will be no hope of resolving the dispute by rational argumentation.

I believe that Hume is here referring to something more important than the odd views of a few eccentric philosophers. As examples of uncompromisable moral issues of disagreement in a contemporary context, we may think of religiously motivated repression of women ${ }^{9}$ and encounters with violent religious fundamentalists. But at a first glance, the idea of artificial lives

\footnotetext{
${ }^{8}$ David Hume, 'The Natural History of Religion', in Hume, A Dissertation on the Passions; The Natural History of Religion: a Critical Edition, ed. Tom L. Beauchamp (Oxford: Clarendon Press), 2007.

${ }^{9}$ Cf. Susan Moller Okin, 'Is multiculturalism bad for women?', in Susan Moller Okin, Is multiculturalism bad for women?, eds. Joshua Cohen, Matthew Howard and Martha C. Nussbaum (Princeton, N.J.: Princeton University Press, 1999), 7-26.
} 
has a ring of arbitrariness. By what criteria can distorted sentiments be distinguished from undistorted, artificial views from natural? And how can Hume admit that religious and philosophical enthusiasts (or some of them) lack the sentiments which morality rests upon, without indirectly conceding the absence of any universal moral standards?

Hume in effect proposes an answer to the first of these two questions in the 'Conclusion' of the second Enquiry. Having introduced the principle that moral value consists in utility or agreeableness to others or oneself, he claims that moral approval and disapproval in common life are always given according to this principle, which is thus 'implicitly maintained' by everyone. People are 'no where, except in the schools, at any loss upon this subject', and when they are, then 'it seems a reasonable presumption, that systems and hypotheses have perverted our natural understanding' (EPM 9.1-9.2; SBN 268-269). ${ }^{10}$ Hence, the criterion for distinguishing artificial from undistorted 'natural' moral views is that they involve the preference of actions and characters that are not useful or agreeable over such that are. For example, causing oneself constant suffering and denying oneself the most innocent pleasures, like Pascal according to Hume's narrator, is evidence of distorted moral sentiments.

This criterion of artificiality fits in with other parts of Hume's moral theory. The propensity to moral feelings can be increased or decreased by education (EPM 5.3; SBN 214) and social intercourse. When societies are formed and begin to interact for mutual benefit, there is a "natural

\footnotetext{
${ }^{10}$ David Hume, An Enquiry Concerning the Principles of Morals (Oxford: Oxford University Press, 1998), abbreviated 'EPM' in the text and cited by section and paragraph, followed by 'SBN' and the page number in Enquiries Concerning the Principles of Human Understanding and Concerning the Principles of Morals, ed. L.A. Selby-Bigge, rev. P.H. Nidditch (Oxford: Clarendon Press, 1975), abbreviated 'SBN'.
} 
progress of human sentiments' in which the rules of justice are extended from the narrow bounds of the individual and his family to the whole society, and then to ever larger groups 'in proportion to the largeness of men's views, and the force of their mutual connections' (EPM 3.21; SBN 192). The more we interact and converse with others, the more we adapt our sentiments to the 'general interests of the community' (EPM 5.42; SBN 228), and so learn to correct first appearances in moral matters just as we do with the evidence of the external senses (EPM 5.4142; SBN 227-229).

Hume thus gives the rough outlines of a psychological theory of how moral sentiments develop which supports the criterion of artificiality, and fits in with the idea of a common or steady and general point of view (EPM 9.6; SBN 272, T 3.3.1.15; SBN 581). ${ }^{11}$ People tend to form incompatible moral judgments because they are influenced by self-interest, relations of friendship or the absence of them, distance in time and space, and certain other factors. We adopt the common point of view by compensating, for instance, for self-interest by considering the consequences of an action for those most strongly affected by it, rather than its effects on ourselves, and for distance in time by imagining how we would feel if we were to meet historical figures here and now rather than just think of them from a temporal distance (T 3.3.1.16; SBN 582). ${ }^{12}$

\footnotetext{
${ }^{11}$ David Hume, A Treatise of Human Nature, ed. David Fate Norton and Mary Norton (Oxford: Clarendon Press, 2000), abbreviated ' $\mathrm{T}$ ' in the text and cited by Book, part, section, and paragraph number, followed by 'SBN' and the page number in A Treatise of Human Nature, ed. L.A. Selby-Bigge, 2nd ed., rev. P.H. Nidditch (Oxford: Clarendon Press, 1978), abbreviated 'SBN' in the text.

${ }^{12}$ On the steady and general or 'common' point of view, cf. Jacqueline Taylor, 'Hume on the Standard of Virtue'.
} 
An implication is that Hume's preference for 'natural' over 'artificial' moral sentiments in the 'Dialogue' should not be read as an exaltation of that which has been left untouched by society, education, and culture over that which has been cultivated. On the contrary, moral virtues and the corresponding sentiments are the result of careful correction of one's pre-reflective and uneducated impulses, which would otherwise make one prefer one's self-interest to the general good, friends to strangers, and so on. What Hume warns against in the 'Dialogue', then, is a perverted form of culture and education where people first become convinced of ill-conceived moral principles, and then arduously mold their behavior and emotional dispositions to those principles, so that in the end 'no one can answer for what will please or displease them'.

\section{Assessing Hume's argument}

I think it is important here to be clear about what Hume's argument against relativism does not establish. It follows from what has just been said that moral judgments and standards cannot be supported by reasons that will convince absolutely everyone, or even constitute valid reasons for everyone. When Hume introduces the controversy between moral rationalists and sentimentalists in the second Enquiry, he explains that the question debated is

whether, like all sound judgment of truth and falsehood, they should be the same to every rational intelligent being; or whether, like the perception of beauty and deformity, they be founded entirely on the particular fabric and constitution of the human species (EPM 1.3; SBN 170).

Hume's answer is of course the latter, by implication, that right and wrong, good and bad, are not

The Journal of Ethics 6, No. 1 (2002), 43-62, and Rachel Cohon, Hume's Morality (Oxford: Oxford University Press, 2008), 126-158. 
the same to every rational intelligent being. This, I think, is a direct consequence of sentimentalism. When all relevant facts of an action or character have been taken into consideration, 'the understanding has no farther room to operate, nor any object on which it could employ itself', and 'the approbation or blame, which then ensues, cannot be the work of the judgment, but of the heart' (EPM App. 1.11; SBN 290). It follows that the justification of moral judgments can only be valid for people with the particular emotional disposition that Hume occasionally calls the moral sense (T 3.1.2; SBN 470, T 3.3.1.25; SBN 588). Nature, he thinks, has made the potential for moral sentiments 'universal in the whole species' (EPM 1.9; SBN 173), but one can imagine rational intelligent non-humans (Vulcans or Klingons, say) who lack the capacity for sympathy and humanity and for whom right and wrong consequently would not be the same as for us, or for whom there would simply exist no right or wrong.

Moreover, Hume recognizes that even some humans, although they possess a potential for sympathy and humanity, or did so at some time, have failed to cultivate it, or have cultivated it in such ways as to eventually develop a preference for the painful over the pleasant, or the useless over the useful. His choice of examples in the 'Dialogue' may give the impression that this happens only in a few exceptional cases. However, nothing excludes the possibility that entire cultures or cultural sub-groups have underdeveloped moral capacities. For example, Hume implies that precisely this was the case with owners of domestic slaves in antiquity when, in a famous passage, he writes that the 'flattery, submission, and low debasement of his slaves' turned the master into a 'petty tyrant' ('Of The Populousness of Ancient Nations', EMPL 384).

How can this be reconciled with Hume's claim that nature has made the moral sense 'universal in the whole species' (EPM 1.9; SBN 173)? To repeat, what Hume calls natural moral sentiments and opposes to 'artificial' ones are the result of education, culture, and social 
interaction, which make us correct and redirect our uneducated impulses and dispositions. What is universal among humans therefore cannot be the actual moral sentiments or emotional dispositions, but only the potential for them. Unfortunately, some people never develop that potential. And moral argumentation, being dependent on feelings, can only touch those who are emotionally disposed in appropriate ways. As Simon Blackburn puts it, we can only hope to persuade decent people - decent according to the standards of those with fully developed capacities for sympathy and humanity, that is. ${ }^{13}$

But if so, what remains of Hume's universalism? What distinguishes it from full-blown relativism? Not surprisingly, the answer depends on what is meant by 'relativism'. William Frankena separates three closely related but logically distinct views by that name. ${ }^{14}$ Descriptive relativism says that different people, cultures, etc. have different and conflicting basic moral views. (That judgments differ on non-fundamental issues is of course not in dispute.) Metaethical relativism says that there is no universally valid justification of one basic moral view against another - no 'Archimedean point' from which conflicting perspectives can be judged neutrally without some particular perspective being presupposed. Normative relativism is the idea that what is right or good for people in one group or tradition may be wrong or bad for people in another - in Hume's terms, that there exist no universal moral standards. To this we may add prescriptive relativism, by which I mean the idea of universal tolerance - that one ought to be 'equally well disposed to everyone's ethical beliefs', as Bernard Williams once put it. ${ }^{15}$

\footnotetext{
${ }^{13}$ Blackburn, Ruling Passions, 304.

${ }^{14}$ William K. Frankena, Ethics. 2. ed. (Englewood Cliffs: Prentice-Hall, 1973), 109-110.

${ }^{15}$ Bernard Williams, Ethics and the Limits of Philosophy (London: Fontana Press/Collins, 1985), 159.
} 
Hume rejects descriptive, normative, and prescriptive relativism. The differences in moral views between cultures are derivative rather than fundamental, there are universal standards for good and bad, right and wrong, and artificial lives, monkish virtues, polygamy and slavery are blameworthy regardless of how well-entrenched they may be in some cultures or sub-cultures (cf. 'Of Polygamy and Divorces' and 'Of the Populousness of Ancient Nations', EMPL 377-464). But for reasons already stated, I believe that Hume's sentimentalism commits him to a certain form of meta-ethical relativism. Those with a fully developed capacity for sympathy and humanity will sometimes find that when they have stated all the facts of a moral matter and all the arguments relevant to it, the hearts of some remain cold, and others respond with sentiments that go against the general good. This may in principle be so even if these emotionally aberrant persons are optimally open-minded and rational, that is, if their reasoning faculties are uncorrupted and well developed although their emotional dispositions are not. If the validity of moral arguments depends on feelings in the way Hume maintains, then moral arguments are not only unconvincing but invalid for such people. That does not make their wrongful actions any less wrong, however.

Blackburn says something similar of Hume's sensible knave, who ignores the rules of justice whenever it suits his self-interest (EPM 9.22; SBN 282-283). From the viewpoint of moral sentimentalism, the knave's defect is not lack of rationality but lack of certain desires, or dispositions to desire.

We can strengthen our determination to make things difficult for those tempted to being knaves. We can exhort the knave to share our sentiments. We can try to turn up the volume of his feelings for 
those whom he exploits. What we cannot do is to argue the knave back into upright behaviour. ${ }^{16}$

The crucial point, I think, is that moral standards can be universally valid even if they are not justifiable for everyone. There can be no neutral point of view from which contesting cultures, traditions, or systems of morality can be assessed without any of them being presupposed from the outset. But it does not follow that right and wrong is relative to traditions. If there is no Archimedean point, then there are only particular points of view from which other points of view can be judged according to the standards of each particular viewpoint. Seen from those viewpoints, some other moral outlooks appear reasonable, perhaps even admirable and possible to learn from, others strange or awkward but morally unobjectionable and tolerable, yet others completely unacceptable - for example, certain forms of religious fundamentalism as seen from a liberal democratic point of view, and vice versa. When the moral standards of others differ from our own, one possibility is that we are right and they are wrong. But as Hume makes clear, it may also be the case that they are right and we wrong, or that the matter is context dependent, or that imprecision in our moral standards leaves room for more than one reasonable view on the matter, or that the issue under debate is a morally indifferent matter of taste. The point of view from which other points of view are seen can itself be open to revision, flexible, perhaps ridden with internal contradictions that call for reflection and self-criticism. The moral thought of a given culture has the capacity to stretch beyond its own boundaries. ${ }^{17}$

\section{Conclusion}

\footnotetext{
${ }^{16}$ Blackburn, Ruling Passions, 209. See also Hume, EMPL 169.

${ }^{17}$ Williams, Ethics and the Limits of Philosophy, 159.
} 
An extreme universalist might hold that any issue of moral disagreement can be resolved by means of rational argument; the disputants just have to look deep enough to find common ground. A weaker position would be that some issues can be resolved rationally and others not, but that even in cases of the last-mentioned kind, it is at least possible to agree rationally to disagree, in the sense that the common ground of assumptions accepted by both parties is found to leave room for more than one rationally defensible view on the issue in debate. Going even further, the universalist may concede that the parties to a disagreement on a moral issue can sometimes be unable to either decide it by argument or agree rationally to disagree about it, but maintain that in such cases there will be reason to reject one view, or possibly both, as deriving from faulty thinking or lack of a fully developed capacity for moral feelings. Hume's moral universalism, I believe, is of the last-mentioned kind.

Contemporary thinkers like Charles Taylor and Richard J. Bernstein have argued that encounters with other systems of beliefs are opportunities to learn from the other by selfreflectively acknowledging and critically scrutinizing one's own fore-understanding - or 'prejudices', in Hans-Georg Gadamer's non-pejorative sense of the word - and to revise them as the result of such critical scrutiny. ${ }^{18}$ Learning of this kind goes both ways. Criticism of the other's pre-reflective beliefs and one's own may provide reasons for giving up one's views in favor of the other's, but also for retaining them and rejecting the other's, or finding both unsatisfactory

\footnotetext{
${ }^{18}$ Hans-Georg Gadamer, Truth and Method, second, rev. ed. J. Weinsheimer and D. G. Marshall (London: Sheed \& Ward, 1989); Richard J., Bernstein, Beyond Objectivism and Relativism: Science, Hermeneutics, and Praxis (Oxford: Basil Blackwell, 1983); Charles Taylor, 'The Politics of Recognition', in Charles Taylor, Multiculturalism: Examining the Politics of Recognition, ed. Amy Gutmann (Princeton, N.J.: Princeton University Press), 25-73.
} 
and taking a third standpoint.

It seems to me that Hume's 'Dialogue' in effect provides a schematic general theoretical framework and methodology for such dialogical integration of perspectives. When I find myself in disagreement with someone from a different tradition over a moral issue and argumentation back and forth does not seem enough to resolve the disagreement, I need to take into consideration the nature of both the other's tradition and my own. What are the background beliefs and attitudes of the other - his 'interests, opinions, passions, and prejudices', as Hume says ('Of the Standard of Taste', EMPL 239) - and, by contrast, of my own time, culture, or group? Are there good reasons for those background beliefs in the external circumstances of the others' conditions of life, their being involved in military contention, for instance? Can shared principles be identified on a more fundamental level, such that on their basis one side can be shown right and the other wrong? If not, does the conflict concern a question which allows no single precise answer, such as the exact limits for incest, or an aesthetic question with no rationally decidable right or wrong answer?

This way of seeing moral disagreement is far from the simple-minded kind of moral universalism that often seems to be the target of relativist attacks. It is still a form of universalism, however. When we critically and self-critically scrutinize the other's position and our own to identify shared moral standards on a more fundamental level, we proceed from the assumption that such standards exist. Dialogical inquiry is the way in which we find the universal standards, or deeper common ground, hidden beneath surface disagreement - that is, in cases where such common ground exists, as opposed to cases of disagreement due to distorted moral sentiments.

Hume is a universalist also in his response to the recognition that there sometimes exists no 
common ground for rational argumentation with the other, or too little of it, so that even the best attempts at dialogue and rational integration of perspectives must fail. If the issue of disagreement is a morally significant one, we then ought to stick to what we after the most careful critical reflection and self-reflection possible find to be right. Thus we do not adopt a stance of relativist tolerance and openness towards superstition, dogmatism, fanaticism, and the 'artificial views' of eccentric philosophers.

What if someone asks 'Why should I choose to view other traditions from the viewpoint of my own, rather than my own from theirs?'. Hume does not consider this possibility, but I think that, depending on the precise meaning of the question, the answer is either that it simply does not makes sense because it presupposes a standpoint outside all traditions from which reasons for such choices could be given, or that, trivially, our own system of moral beliefs is better according to our own standards, or that in fact we ought to see and evaluate our own tradition from the perspective of certain others, although there is no other way to do this than by ultimately applying our own standards in a kind of critical self-reflection where other possibilities are imagined, as in Montesquieu's Persian Letters, a satirical description of $18^{\text {th }}$ century Europe through the eyes of a group of Persian visitors. ${ }^{19}$ However, none of this implies that the standards of the others are right 'for them' and our standards only right 'for us'.

\section{References}

\footnotetext{
${ }^{19}$ Charles-Louis de Secondat Montesquieu. Persian Letters, transl. from the French, in two volumes, sixth ed. Printed by Alexander Donaldson, London and Edinburgh, 1773.
} 
Abramson, Kate . 'Hume on Cultural Conflicts of Values', Philosophical Studies 94, No. 1-2, 1999, 173-187.

Beauchamp, Tom. 'Introduction. A History of the Enquiry on Morals', in David Hume, An Enquiry Concerning the Principles of Morals, ed. Tom Beauchamp. Oxford: Oxford University Press, 1998.

Bernstein, Richard J. Beyond Objectivism and Relativism: Science, Hermeneutics, and Praxis. Oxford: Basil Blackwell, 1983.

Blackburn, Simon. Ruling Passions: A Theory of Practical Reasoning. Oxford: Oxford University Press 1998.

Cohon, Rachel. Hume's Morality. Oxford: Oxford University Press, 2008.

Frankena, William K. Ethics. 2. ed. Englewood Cliffs: Prentice-Hall, 1973.

Gadamer, Hans-Georg. Truth and Method, second, rev. ed. J. Weinsheimer and D. G. Marshall. London: Sheed \& Ward, 1989.

Hume, David. 'A Dialogue', in Hume, An Enquiry Concerning the Principles of Morals, 110123.

Hume, David. An Enquiry Concerning the Principles of Morals. Oxford: Oxford University Press, 1998. (References in the text are also to the same work, ed. L.A. Selby-Bigge, rev. P.H. Nidditch. Oxford: Clarendon Press, 1975.).

Hume, David. Essays, Moral, Political, Literary, ed. Eugene F. Miller. Indianapolis: Liberty Fund, 1987.

Hume, David . 'The Natural History of Religion', in Hume, A Dissertation on the Passions; The Natural History of Religion: a Critical Edition, ed. Tom L. Beauchamp. Oxford: Clarendon Press, 2007. 
Hume, David. A Treatise of Human Nature, ed. David Fate Norton and Mary Norton, Oxford: Clarendon Press, 2000. (References in the text are also to the same work, ed. L.A. SelbyBigge, 2nd ed., rev. P.H. Nidditch, Oxford: Clarendon Press, 1978.).

Mazza, Emilio. 'Cannibals in “A Dialogue” (In Search of a Standard for Morals)', in Instruction and Amusement: Le ragioni dell'illuminismo britannicco, eds. Emilio Mazza and Emanuele Ronchetti. Padova: Il Poligrafo, 2005, 45-66.

Moller Okin, Susan . 'Is multiculturalism bad for women?', in Susan Moller Okin, Is multiculturalism bad for women?, eds. Joshua Cohen, Matthew Howard and Martha C. Nussbaum. Princeton, N.J.: Princeton University Press, 1999, 7-26.

Montesquieu, Charles-Louis de Secondat, Persian Letters, transl. from the French, in two volumes, sixth ed., printed by Alexander Donaldson, London and Edinburgh, 1773.

Taylor, Charles. 'The Politics of Recognition', in Charles Taylor, Multiculturalism: Examining the Politics of Recognition, ed. Amy Gutmann. Princeton, N.J.: Princeton University Press, $25-73$.

Taylor, Jacqueline. 'Hume on the Standard of Virtue', The Journal of Ethics 6, No. 1, 2002, 4362.

Williams, Bernard. Ethics and the Limits of Philosophy. London: Fontana Press/Collins, 1985.

Biographical note

Henrik Bohlin (henrik.bohlin@sh.se) is associate professor of philosophy at Södertörn University, Stockholm, Sweden. He has published works on Hume's philosophy, empathy, critical thinking, epistemology, and philosophy of education. 